\section{Cognitive vision, its disorders and differential diagnosis in adults and children: knowing where and what things are}

GN Dutton ${ }^{1,2}$

\section{Abstract}

As ophthalmologists we need a basic model of how the higher visual system works and its common disorders. This presentation aims to provide an outline of such a model. Our ability to survey a visual scene, locate and recognise an object of interest, move towards it and pick it up, recruits a number of complex cognitive higher visual pathways, all of which are susceptible to damage. The visual map in the mind needs to be co-located with reality and is primarily plotted by the posterior parietal lobes, which interact with the frontal lobes to choose the object of interest. Neck and extraocular muscle proprioceptors are probably responsible for maintaining this co-location when the head and eyes move with respect to the body, and synchronous input from both eyes is needed for correct localisation of moving targets. Recognition of what is being looked at is brought about by comparing the visual input with the 'image libraries' in the temporal lobes. Once an object is recognised, its choice is mediated by parietal and frontal lobe tissue. The parietal lobes determine the visual coordinates and plan the visually guided movement of the limbs to pick it up, and the frontal lobes participate in making the choice. The connection between the occipital lobes and the parietal lobes is known as the dorsal stream, and the connection between the occipital lobes and the temporal lobes, comprises the ventral stream. Both disorders of neck and extraocular muscle proprioception, and disorders leading to asynchronous input along the two optic nerves are 'peripheral' causes of impaired visually guided movement, while bilateral damage to the parietal lobes can result in central impairment of visually guided movement, or optic ataxia. Damage to the temporal lobes can result in impaired recognition, problems with route finding and poor visual memory. Spontaneous activity in the temporal lobes can result in formed visual hallucinations, in patients with impaired central visual function, particularly the elderly. Deficits in cognitive visual function can occur in different combinations in both children and adults depending on the nature and distribution of the underlying brain damage. In young children the potential for recovery can lead to significant improvement in parietal lobe function with time. Patients with these disorders need an understanding of their deficits and a structured positive approach to their rehabilitation.

Eye (2003) 17, 289-304. doi:10.1038/

sj.eye. 6700344

Keywords: dorsal stream; ventral stream; Charles Bonnet syndrome; palinopsia; prosopagnosia; optic ataxia

\section{Introduction}

The way we see and interpret the world around us and the way in which we move through the visual scene has puzzled philosophers for centuries. There is now, however, a rapidly increasing knowledge base about how the visual system works and how it can go wrong. ${ }^{1,2}$ As ophthalmologists our principal work concerns the management of disorders of the eye and the visual pathways, but not infrequently we see patients whose visual problems relate to disorders of higher visual processing and are complex and enigmatic. These patients may have difficulties moving

\author{
${ }^{1}$ Tennent Institute of \\ Ophthalmology \\ Gartnavel General Hospital \\ Great Western Road \\ Glasgow, UK \\ ${ }^{2}$ The Royal Hospital for \\ Sick Children \\ Yorkhill \\ Glasgow, UK \\ Correspondence: \\ GN Dutton \\ Tennent Institute of \\ Ophthalmology, \\ Gartnavel General Hospital, \\ Great Western Road, \\ Glasgow G12 OYN, UK \\ Tel: + 441412112937 \\ Fax: + 441412116290 \\ E-mail: sheena.mackay@ \\ northglasgow.scot.nhs.uk
}

Received: 18 June 2002 
accurately through visual space, difficulties handling complex visual scenes, problems recognising certain aspects of the world around them, or they may be troubled by seeing visual phenomena that they know not to be present. As ophthalmologists we tend not to see such individuals when they have additional neurological pathology because they come under the care of our medical colleagues, but those whose complaints are primarily visual present to us. The aim of this paper is to describe the conditions in adults and children which can lead to misinterpretation of where we are with respect to the visual scene which surrounds us, or misunderstanding of what we are looking at. The question is, how can we, as busy clinicians with short consultation times, identify such problems and provide strategies which will prove helpful to our patients? (In this presentation, the term cognitive visual disorder is used in its broadest sense to refer to a condition leading to misinterpretation of the visual world either with respect to where things are or concerning what things are.)

\section{A basic practical clinical model of the higher visual system}

\section{Analysing the visual scene and giving attention}

While we are alert, our minds are being bombarded with visual information. Somehow we have to be able to cope with it all. We deceive ourselves that we are consciously aware of everything that is going on around us, but this is not the case. Our posterior parietal lobes serve the function of appraising the overall visual scene and (in cooperation with the temporal lobes (for recognition) and the frontal lobes (for mediating choice), electing which element of the visual scene to attend to at any one time. ${ }^{3}$

\section{Planning and bringing about visually guided movement}

We take it for granted that we know where we are with respect to the objects that surround us and that we can see, for example, a pencil in the peripheral visual field. We can choose to shift our gaze to look at it, and reach out and pick it up, but when one stops to think about it, this mundane routine action is remarkable. The visual scene is processed within the brain but it is appreciated by the mind as being external to the body. The image of the pencil on the peripheral retina provokes an accurate fast eye movement and head turn to the new location. The coordinates for this action are determined from the image in the mind and are conveyed to the arm and hand. ${ }^{3}$ This is known as efference copy. The hand is then instructed to move towards the pencil and at the same time the fingers become orientated to the position of the pencil and separated to exactly the right amount ready to pick it up. The hand stops at the right distance from the body, the pencil is grasped and picked up. The processes involved, include motor control, cerebellar coordination, on-line feedback both through vision and through proprioception of the musculature, combined with labyrinthine control to maintain balance. All of these on-line control mechanisms take place subconsciously.

\section{Moving the visual map - neck and extraocular muscle proprioception}

In order to look at the pencil, the eyes rotated within the head and the head rotated with respect to the body, yet this did not disturb the accuracy with which the pencil was picked up. This is thought to be brought about by a form of proprioceptive feedback from both the neck ${ }^{4}$ and the extraocular muscles, ${ }^{5}$ which relocates the efference copy map to match the amount of head and eye rotation with respect to the body. It is therefore not surprising that patients with neck pathology, ${ }^{6}$ squint ${ }^{5}$ and restricted eye movements ${ }^{7}$ may have a sensation that the visual surroundings are not quite where they think they are, leading to a sense of imbalance and clumsiness. The symptoms are difficult to describe because these are subconscious automatic functions that are disordered. A very similar effect is brought about by spectacle correction of aphakia, for which the efference copy map has to be recalibrated to re-establish accurate movement of the limbs within the newly magnified and distorted picture that is presented to the mind.

\section{Recognising what is seen}

The medial temporal lobes ${ }^{2}$ provide us with a visual library that is constantly being updated. When a person or an object is seen for the first time the 'picture' is stored ready for subsequent recall, but when the person or object are well known, recognition takes place. Both medial temporal lobes participate in both activities, but in the context of focal pathology, face recognition and orientation appears to show right-sided dominance, ${ }^{8-13}$ whereas shape and object recognition, and the recognition of text appear to show left-sided dominance. ${ }^{14,15}$ Damage to the temporal lobes can therefore result in a variety of patterns of impaired recognition with right-sided damage being more likely to cause impaired face recognition (prosopagnosia) and left-sided damage being more likely to cause impaired shape and object recognition ${ }^{16}$ perhaps associated with difficulties with reading. Bilateral damage associated with a combination of problems is, however, more common than unilateral damage. 


\section{Route finding}

The temporal lobes also serve the function of storing route maps. (The map is multi-modal. Blind people, for example, are able to navigate despite lack of vision.) The orientation required for route finding is needed for finding one's way around both outside and inside and for being able to find things. The right temporal lobe may predominantly serve this function as in the recognition of faces. $^{12}$

\section{Integrating the processes of recognition, simultaneous} perception, attention, selection, and action

Visual information is primarily processed in the occipital cortex from where it is passed to two principal locations, the posterior parietal lobes (whose functions are to process the whole visual scene and to cooperate with the frontal lobes to accord attention to areas of interest and to plan motor action) and the temporal lobes (which are responsible for according recognition to what is being looked at). Recent research has converged on the concept, that from a functional point of view at least, there are two pathways, the dorsal stream, which links the visual cortex with the parietal lobes, and the ventral steam, which links the visual cortex with the temporal lobes (Figure 1). However, functional magnetic resonance imaging studies indicate that these two substrates are closely interlinked. ${ }^{17}$

When the pencil was picked up, the dorsal stream passed the whole visual scene to the parietal lobes and attention was given to the pencil, which was recognised via the ventral stream pathway and the temporal lobes.

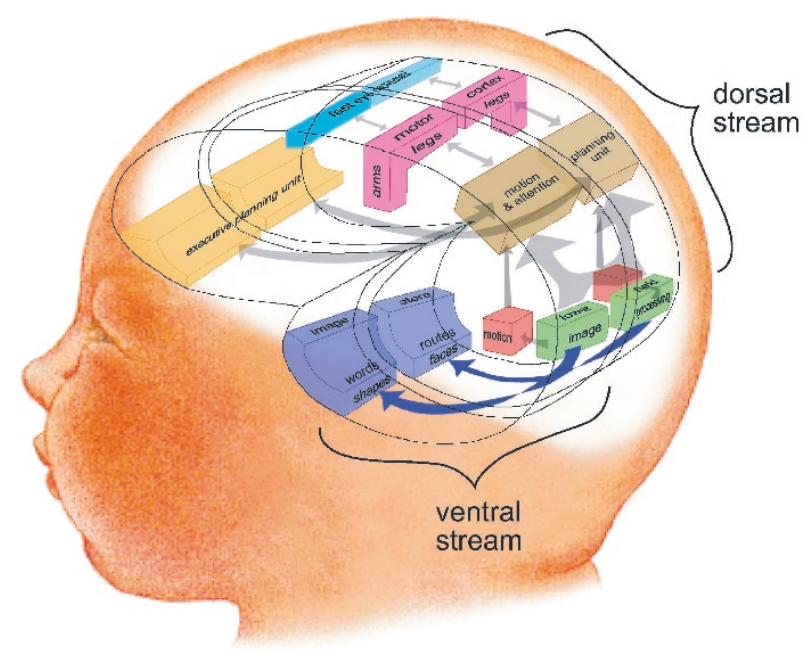

Figure 1 Stylised diagram of the brain illustrating the generic locations and interactions between the structures that serve higher visual processing.
The frontal lobes mediated the choice to pick the pencil up. The dorsal stream instructed the motor cortex where to reach, how far to reach and how to position the hand and fingers to grasp the pencil and the task was accomplished. Any part of this process in any combination can be disrupted by brain pathology.

\section{Remembering what is seen and visual imagination}

The act of copying information requires visual memory, as do a host of daily activities. The structures that serve this function include the hippocampi and the temporal and frontal lobes. The act of thinking about specific nouns leads to activity in structures within the inferior portion of the temporal lobes (in particular the fusiform gyrus), ${ }^{18}$ along with frontal working memory areas. ${ }^{19}$

Active visual working memory is a function of the fusiform gyrus of the temporal lobe in association with the inferior frontal gyri. ${ }^{20}$ Ventrolateral areas are involved mainly in working memory for objects and dorsolateral areas are involved mainly in working memory for spatial locations. ${ }^{21}$ Recent experiments suggest that not only bottom-up signals from the retina but also top-down signals from the prefrontal cortex can trigger the retrieval of visual memories from the temporal lobes, which may serve as a neural basis for conscious recall. ${ }^{22}$

\section{Conscious and subconscious vision}

You are driving along an urban road and a child runs out in front of your car. You swerve and the child is safe. Conscious thought may not have been used to initiate your action. In primitive animals vision is primarily served by the superior colliculi whereas in higher animals the striate cortex and the higher visual pathways have largely taken over this function, but not completely. ${ }^{3}$ In man the superior colliculi are connected to the retina by the retino-tectal tract which probably functions along with the pulvinar to serve such reflex vision that is required for selfprotection. This reflex visual function may still persist in both adults and children with cortical visual loss.

\section{Clinical presentations}

\section{Clinical presentations in adults}

Bumping into things: the Pulfrich phenomenon Delayed retinal processing or delayed conduction from one eye with respect to the other leads to a temporal mismatch of the incoming visual information, which leads to inaccuracy of perception of the position of moving targets in three-dimensional space. ${ }^{23}$ This results in an 
inappropriate compensatory movement of the limbs or body (Figure 2). While this can be considered a peripheral disorder, it is the central interpretation of where things are in visual space that is disturbed and causes problems.

There are a number of presenting complaints that we have found to be common to the diagnosis of the Pulfrich phenomenon. These include:

- Swerving inappropriately to avoid oncoming traffic (when the right eye is affected) or parked traffic (when the left eye is affected).

- A tendency to knock off wing mirrors of parked cars (left eye affected).

- Being unable to replace the tape in a tape recorder whilst driving, because the car is then driven in the wrong direction.

- Feeling a need to duck and swerve when going through doorways.

- In crowds, swerving to avoid people on the affected side and bumping into people on the other side.

- Difficulty with fine tasks such as tapestry.

- Difficulty in accurately reaching for door handles.

- A sensation that lamp-posts are coming to hit one when sitting upstairs on a double decker bus!

Causes of the Pulfrich phenomenon include dilatation of one pupil (a driving hazard?), demyelinating, traumatic and ischaemic optic neuropathy.

A number of years ago we reported the successful management of a patient with the Pulfrich phenomenon using a pair of glasses with one tinted lens calibrated to prolong the retinal processing time to match the delay on the other side. She still wears these glasses all the time, and we have since managed many similar patients in the same way. Another such patient was in a road traffic accident but was frightened to drive again and had even received psychiatric help. The prescription of spectacles with an appropriately tinted lens in front of the unaffected eye solved her problem instantly! ${ }^{24,25}$

Hemianopia and hemianopic blindsight Brain injuries sustained by soldiers during the First World War led skilled observers such as Gordon Holmes ${ }^{26,27}$ and George Riddoch ${ }^{28}$ to relate the sites of brain damage to the pattern of visual field loss, which is the basis of our current knowledge of the retinotopic map in the visual cortex.

Riddoch also found that some soldiers with hemianopia due to brain injury were aware, at an ostensibly subconscious level, of intact movement perception in the 'blind' hemifield, a phenomenon known as statokinetic dissociation or the Riddoch phenomenon. He also showed that recovery of perception of movement is a good prognostic sign for further recovery. The term blindsight was first coined by Weiskrantz ${ }^{29}$ who carried out detailed studies of the persistent visual function in the hemianopic field of a patient who had undergone surgical removal of the right striate cortex.

A practical way of detecting intact perception of movement in a 'blind' hemifield is to carry out Goldmann perimetry. The patient is instructed to look at the peripheral target as soon as it is first seen (rather than to press the buzzer) and the eye is viewed by the observer. Isopters, which join the points at which saccades are generated, can then be plotted. Patients who are able to do this can be trained to improve the reproducibility and accuracy of their saccades on the perimeter. ${ }^{30}$ Patients who are aware of their hemianopia can also be trained to use large fast eye movements into the blind hemifield, which results in long-term improvements in visual searching and scanning, with associated subjective improvements in visual function in day-to-day life. Patients with stroke receive physiotherapy and speech therapy but such 'visuotherapy' has yet to be developed significantly outside the context of research.

Cerebral blindness and blindsight The following case history gives an insight into the features of persistent, to a large extent subconscious vision, which can be present in those who have lost vision due to bilateral occipital damage.

MC was a skilled personal secretary in her thirties. As a sequel to severe respiratory infection and hypotension she developed bilateral occipital lobe infarctions. We first saw her 1 year later. She was escorted into the clinic by her husband and told us that she had no vision. Indeed she had no vision for anything that was not moving, but both she and her husband were astonished when she accurately named the colours of large moving objects, and when she was able to accurately mirror hand movements being made in front of her with movements of her own hands. However, she was even more surprised that she was able to walk accurately around a number of obstacles placed in her path, when she was encouraged to do so and told that she could. Since then she has learned to move her head from side to side to be able to visualise things in front of her, and she has successfully followed up our suggestion of using a rocking chair to enhance her perceptual abilities. Her descriptions of her vision are fascinating. She can see rainwater running down a window but cannot see through it. When her daughter is walking away from her she can see the pony tail moving from side to side but cannot see her daughter. She can see the movement of the water going down the plug hole but she cannot see her 


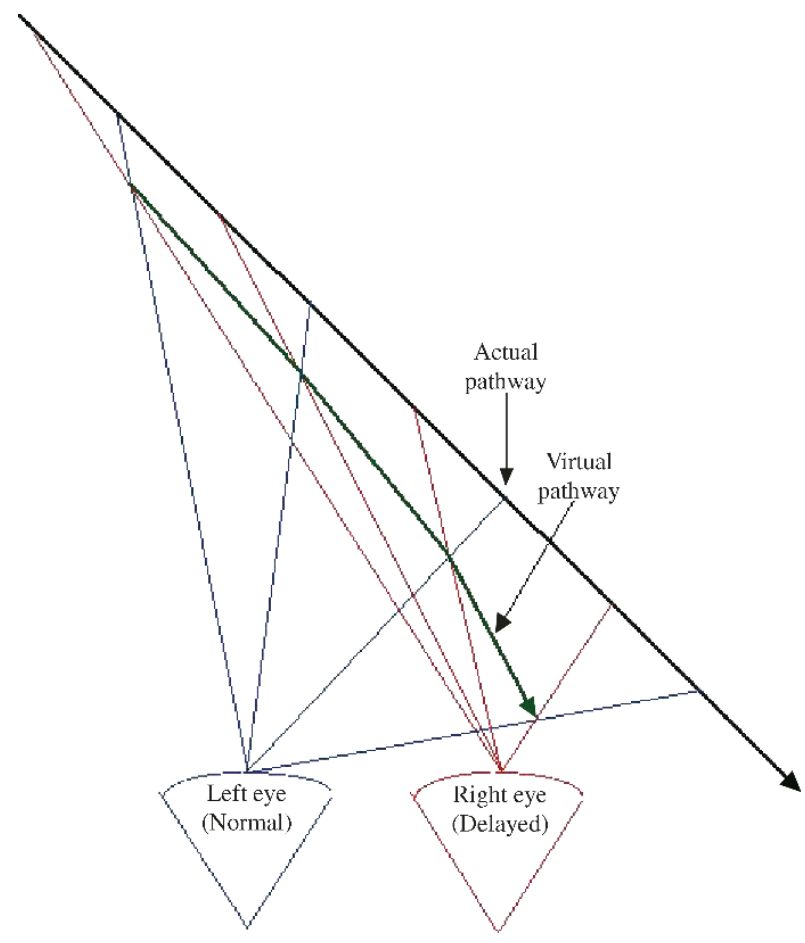

Figure 2 Diagram illustrating the way in which the Pulfrich phenomenon causes an object approaching an eye with delayed conduction to appear to vear towards the affected side. The left eye (blue) 'sees' the approaching target ahead of the affected left eye (red). The pathway perceived by the mind is shown in green.

child in the bath. These phenomena were apparent to her before she came to see us, but because she had been told she was blind, she did not have the confidence to believe her own observations. The act of informing her that her experiences were fully in accordance with the concept of intact function in the areas of the visual brain responsible for seeing motion and the dorsal stream pathways responsible for ostensibly subconscious visually guided movement, gave her an understanding of the world as she sees it and now, 2 years later, she is able to navigate within her home independently. It seems that the act of drawing her awareness to her own subconscious vision has been the catalyst to the initiation of her (albeit incomplete) functional rehabilitation.

Impaired simultaneous perception, loss of attention and inaccurate visually guided movement Rather than discuss contemporary work, ${ }^{1-3,31}$ for this section I thought I would return to the work of Gordon Holmes ${ }^{27}$ published in the British Journal of Ophthalmology in 1918. In an extraordinarily detailed paper he gives the clinical descriptions of six soldiers in whom shrapnel or bullets passed through both posterior parietal lobes. In all six patients, bilateral lesions involved the angular and supramarginal gyri and the splenium internally. Lower visual field loss was seen in four patients due to injury of the superior optic radiations. The cognitive visual problems were very similar in all the cases and closely resembled those described by Balint a few years earlier in a patient with bilateral ischaemic damage to the parietal lobes. $^{32}$

The common features were:

- An inability to make accurate visually guided movement of any part of the body. This Holmes described as a disturbance of visual orientation and Balint referred to it as optic ataxia (for movement of the upper limbs).

- An inability to see more than one or two elements of the overall visual scene - a manifestation described by Balint as simultanagnosia.

- An inability to explore a scene with the eyes and to shift gaze from one location to another (apraxia of gaze).

These features, which may be associated with lower visual field loss (due to the superior optic radiations also being affected), are consistent with profound injury to what is now known as the dorsal stream.

In our clinics, however, patients are more likely to present with more subtle deficits of simultaneous perception as their sole problem. The clue to the diagnosis is the patient who says she is unable to read, but who has a good binocular visual acuity for single letters. Two L-shaped occluders can be used to reveal only one or two words at a time. If this allows the text to be read and the meaning is understood, but revealing more words causes confusion, the diagnosis of bilateral parietal dysfunction should be suspected. In our experience this condition is not uncommon but may go unrecognised. Multifocal ischaemic pathology is the most common cause. Some success has been claimed for intensive rehabilitation. ${ }^{33}$

Children with impaired vision due to periventricular leukomalacia commonly show a very similar pattern of visual dysfunction ${ }^{34}$ and this is discussed later.

Lack of attention and driving Profound impairments in simultaneous perception and attention due to parietal lobe pathology are rare, but more minor disorders of these functions are relatively common. This has been highlighted by recent work investigating attention in the context of driving. The investigation called the 'Useful Field of View' assesses ability to give attention to a brief event in the eccentric visual field while also giving attention to a central event. It investigates visual processing speed and visual attention. Those with low scores are at significantly greater risk of being involved in road traffic accidents. ${ }^{35}$ 
Not recognising people and getting lost The temporal lobes contain the visual memory banks and allow us to recognise what we are looking at. The process of recognition is served on both sides, but there is a degree of lateralisation of function, with the fusiform gyrus of the right temporal lobe ${ }^{36,37}$ primarily serving the function of recognition of people's faces ${ }^{9-13,38}$ (except perhaps in left-handed people). ${ }^{39}$ Damage to this area ${ }^{40,41}$ or the adjacent white matter ${ }^{42}$ leads to problems with face recognition or prosopagnosia. There is a range of different patterns. ${ }^{38}$ The disorder can be complete or incomplete, or there can be inability to identify faces of new people encountered after the time of the brain damage, indicating an inability to form a memory store of new faces. ${ }^{43}$ False recognition of unfamiliar faces is a problem for some people with prosopagnosia. ${ }^{44}$ The act of not recognising someone is a complex task. Each person one passes on the street is compared with the memory bank of stored faces, if there is not a match, that person is not recognised. An incorrect match leads to false recognition. There may also be difficulties with object recognition. ${ }^{45}$ Recognition of the language significance of facial expression can be preserved ${ }^{10}$ or impaired ${ }^{46}$ both in adult acquired cases and as a result of brain damage during infancy. ${ }^{47}$

Prosopagnosia can also occur developmentally ${ }^{48,49}$ in association with normal imaging ${ }^{50}$ or with a smaller than normal right temporal lobe ${ }^{51}$ and can be a fundamental problem for children and adults alike. (A number of people with developmental prosopagnosia have introduced themselves to this author. They describe the profound problems of not being able to recognise their own children and spouses, and the lengths they have gone to disguise their disability. Other family members have been described as having the same problem and/or profound problems finding their way around.)

An inability or disability in finding one's way around (topographic agnosia) due to right temporal lobe dysfunction, ${ }^{12}$ in our experience, is characterised by problems when out and about, difficulties finding the way around in buildings, and problems knowing where things are in drawers and cupboards. The orientational problems are not just visual. There can also be a loss of knowledge about well-known buildings and landmarks when tested from their spoken name.

Prosopagnosia and topographic agnosia commonly occur together ${ }^{12}$ and the combination has been reported as a manifestation of migraine. ${ }^{52}$

Impaired reading ability An acquired impairment in reading ability can be caused by a wide range of disorders. ${ }^{2}$ When an adult patient says that he has developed difficulty reading in the context of good visual acuity, possible factors to consider are:
- Hemianopia. The hemianopia moves as the eyes move. Right hemianopia means that the next word may not be seen. Left hemianopia means that the start of the next line cannot be seen. Vertical reading can help some people considerably, both for hemianopia and for hemianopic neglect due to contalateral parietal pathology.

- Alexia. Left occipital infarction extending into the splenium also disconnects the right occipital lobe from the language processing centres on the left side of the brain. This results in inability to read despite the ability to write being maintained.

- Impaired simultaneous perception due to parietal pathology means that only a few words can be read at once.

- Acquired dyslexia can take many forms and can result from temporal lobe damage resulting in impaired word recognition (particularly with pathology on the left side ${ }^{14,15}$ ) and from frontal damage, which can impair language interpretation and visual working memory. ${ }^{19}$

Table 1 shows a practical approach one can use in the clinic to determine the cause of acquired reading difficulty.

Persisting vision If a patient continues to see the details of a visual scene even after looking away from it, this is known as visual perseveration or palinopsia. This condition can occur as a sequel to anterior visual pathway disturbance ${ }^{53}$ or as a variant of the Charles Bonnet syndrome ${ }^{54}$ but it can also occur as a result of focal occipital or occipito-parietal pathology (more commonly on the right). ${ }^{55-60}$ Patients can also complain of persistence of their visual imagery as a sequel to a range of psychotherapeutic drugs ${ }^{61-63}$ or following the use of LSD or ecstasy. ${ }^{64,65}$ It is important to be able to make a correct diagnosis because patients with palinopsia have been misdiagnosed as being psychotic. ${ }^{66}$ For some patients the condition can be disabling and anticonvulsant treatment, for example with carbamazepine, warrants consideration. ${ }^{67}$

\section{Diffuse brain disorders}

- Progressive acquired dorsal and ventral stream dysfunction Patients with progressive damage to the posterior cortex may develop damage to the dorsal stream system or to the ventral stream system, or both. ${ }^{68}$

- Progressive dementia (for example, caused by Altzheimer's disease and posterior cortical atrophy) can affect any aspect of visual function. Loss of visual acuity and contrast sensitivity are increasingly being recognised. ${ }^{69,70}$ Visual field loss in Altzheimer's disease tends to affect the lower visual fields in an 
Table 1 A practical approach to assessing acquired reading difficulties
A. Anterior visual pathways
1. Poor corrected visual acuity
Measure visual acuity, and ensure text can be seen by enlargement, magnification and lighting.
2. Reduced paracentral vision
Test for paracentral scotomata with an Amsler grid. Determine the degree of enlargement and orientation of text that can best be read.

\section{B. Posterior visual pathways}

3. Hemianopia, other visual field loss, hemianopic neglect and alexia

Assess visual fields and identify (if possible) any reading strategy which circumvents the problem. For example, vertical reading downwards for right hemianopia and upwards for left hemianopia (so that the patient can read into the sighted visual field).

Right hemianopia may be associated with a total inability to read (alexia).

\section{Dorsal stream pathways}

4. Impaired simultaneous perception with or without apraxia of gaze

Ask the patient to read text and watch the eye movements at the same time. Progressively mask off text until reading is accomplished. Consider using two L-shaped masks for text and/or presenting text sequentially on a computer screen (eg Acereader, available on the internet).

\section{Ventral stream pathways}

5. Cognitive visual problems

Ask the patient to read a passage out loud. Ask for an interpretation of what has been read. Identify hesitations, inability to read words, the use of incorrect or alternative words and misinterpretation of words.

\section{E. Motor pathways}

\section{Problems with accommodation}

Dynamic retinoscopy (while the patient looks at a near target at different distances) elicits whether accommodation is taking place (eg in an emmetrope, a working distance of $0.5 \mathrm{~m}$ leads to +2.00 retinoscopic value, but with a target at $20 \mathrm{~cm}$ leads to a net -3.00 retinoscopic value). Impaired accommodation can thus be detected.

7. Problems with eye movement control

Small repeated horizontal saccades are required for reading. We have found that acquired disorders of such movements (which can be observed while the patient is reading) can lead to difficulty reading small print but not large print.

arcuate manner ${ }^{71}$ and impaired motion perception has been demonstrated. ${ }^{72}$ Degenerative foci in the occipito-parietal area affecting dorsal stream structures can cause great difficulty with visually guided movement ${ }^{73-75}$ associated with impaired simultaneous perception, which is gradually progressive $^{76,77}$ and can be the first sign of dementia. ${ }^{76}$ When the occipito-temporal areas (the ventral stream) are affected, alexia, impaired object and face recognition, ${ }^{78-88}$ and problems finding the way around $^{89,90}$ can be extremely problematic.

\section{- Multiple sclerosis can cause difficulties with} recognition and identification of objects. The problems include impaired recognition of shape, together with difficulties with identification and naming ${ }^{91}$ and can result from occipito-temporal demyelination..$^{92}$ Visuospatial problems are also common. ${ }^{93}$ Busy supermarkets can be visually overwhelming and patients may not understand why they have to rest after going out shopping while a walk in the park is not so tiring. The focal nature of the pathology means that the problems differ from individual to individual and can affect both those who are cognitively impaired and those who have few other neurological problems.
Visual hallucinations associated with poor vision: the Charles Bonnet syndrome Lack of visual input can result in the mind creating its own imagery. Prolonged patching of the eyes can lead to both unformed and formed (or complex) visual hallucinations that abate when the patches are removed. Similarly, visually impaired patients may experience complex visual hallucinations. This condition is known as the Charles Bonnet syndrome (named after the author who first described the condition in his grandfather). ${ }^{94}$

The hallucinations comprise clear organised images, which appear real in three-dimensional space, over which the subject has little control. They are thought to represent release phenomena due to loss of input from the central visual fields to the visual association areas of the cerebral cortex. Reduced cognitive function accompanying old age, social isolation, and sensory deprivation may be contributory factors.

The most common hallucination is of a person. Disembodied distorted faces, small costumed figures and branching structures, realistic images of animals and figures, subtle geometric forms, well-defined complex figures, faces which can be Lilliputian (miniaturised), 
normal sized or 'larger than life' in black and white, or more commonly, in colour, of varying degrees of complexity have also been described. ${ }^{54}$ Functional MRI carried out during hallucinations has shown activity in the ventral occipital lobe tissue with type of hallucination correlating with the known functional anatomy of the occipital lobe. ${ }^{95}$

Charles Bonnet syndrome is most common in those with age-related macular degeneration. It frequently goes unrecognised in clinical practice because of both a lack of awareness among doctors and patients' reluctance to admit to hallucinations in case they are thought to be mentally unstable. Patients usually possess insight into the unreality of their visual experiences, which can be pleasant but can cause distress.

Sensitive and sympathetic history taking is required to make the diagnosis. We are finding that as many as $60 \%$ of patients with age-related macular degeneration with a visual acuity of $6 / 36$ or worse, if carefully questioned, will describe hallucinations. Reassurance and explanation that the visions are benign and do not signify mental illness have an important therapeutic effect. Improving visual function and addressing social isolation may terminate hallucinatory activity. There is no universally effective drug treatment but anticonvulsants may play a limited role in aborting the hallucinations.

Case report of a patient with a parieto-occipital intra-cerebral haemorrhage In 1999 a 66-year-old lady sustained an intracerebral haemorrhage (Figure 3). Since then she had had profoundly disturbed vision, which had not been explained to her. When seen recently she described difficulty recognising people's faces and problems of falsely recognising people she does not know. These symptoms are worst when she is under stress. Intermittently she sees people as having the heads of dogs, which are entirely realistic, or people may, on occasion, appear to have no arms. She may see formed visual hallucinations of people standing in front of her. She has great problems finding her way around, both when out and about and in people's homes. She also tends to lose things around the home. The visual acuities are 6/9 unaided in each eye and she has a complete left homonymous hemianopia. This patient has a combination of prosopagnosia, topographic agnosia, Charles Bonnet syndrome and left hemianopia occurring as a sequel to her intracerebral haemorrhage. Explanation of her symptoms combined with suggested strategies for handling her problems have considerably improved her quality of her life.

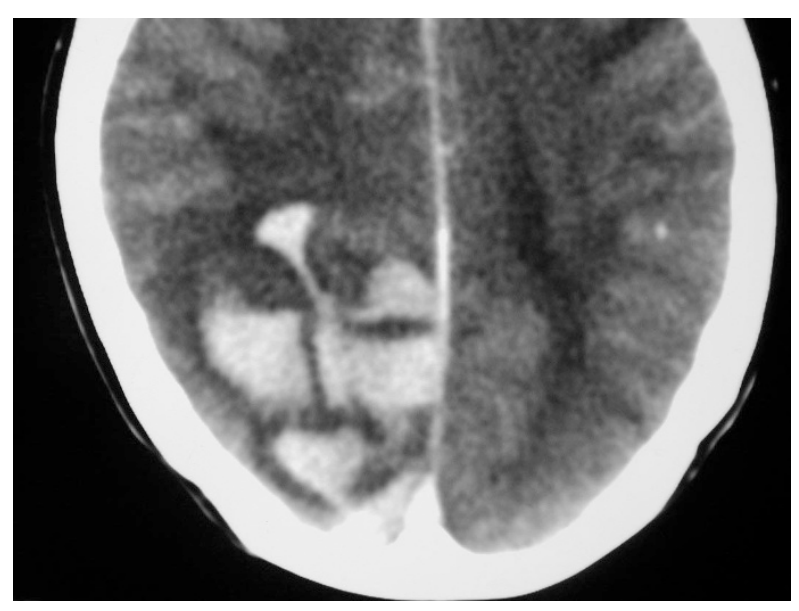

Figure 3 Axial MRI scan showing an intracerebral haemorrhage, which was found on the other images to extend through the right occipital lobes into the right parietal and temporal lobes.

\section{Clinical presentations in children}

Clumsiness in children with squint The parietal visual function of mapping three-dimensional visual space so that we can move through it gradually develops as we get older. Young children commonly bump into things and it is difficult to know whether a history of bumping into things as a young child is normal or whether the incoordination is visual in origin.

Parents of children who have a squint commonly say that their children have better hand-eye coordination when their eyes are aligned. For this reason we set out to investigate whether accommodative esotropia leads to inaccuracies of movement of the upper limbs. ${ }^{96}$ We set up a touch screen and asked children with either right or left fully accommodative esotropia to point at targets on the screen without being able to see their hands. They were tested when their eyes were aligned (while wearing spectacles) and when they were squinting (while not wearing spectacles). Hypermetropic children without squint made up the control group and they too were tested with and without spectacles. The result was that the children with accommodative esotropia pointed inaccurately to the side of the central target erring to the side of the straight eye (when not wearing glasses) but they were more accurate and not different from the controls when the squint was corrected by wearing glasses, thus validating the parents' observations. We suggest that the oculomotor imbalance disturbs the position of the efference copy map, perhaps by disturbing the normal proprioceptive input from the extraocular muscles, which may contribute to co-aligning the picture of the world as we see it, with the real world outside our bodies. (Adults with acquired squint 
commonly complain of mislocalisation of objects in visual space, presumably for similar reasons.)

Not seeing things that are obvious Books for young children do not contain a lot of information on each page and the print is large. Magic for young children is easy to perform because they do not notice change in the same way as adults. A young child on a bike shouts 'get out of the way' when there is plenty of room. These observations reflect the nature of the developing parietal lobe functions of simultaneous perception, attention and planning movement through three-dimensional space, with the capacity to handle complex visual data progressively increasing with age. ${ }^{97}$ But what happens when there is pathology in this area of the brain? Children with dorsal stream dysfunction (which in our experience is most commonly due to periventricular leukomalacia ${ }^{34}$ ) can show many features related to dysfunction in this area, which causes difficulty in handling complex visual scenes (Table 2). Finding a toy from amongst other toys or on a patterned carpet or bedspread can be very difficult or impossible. Difficulty in seeing things that are pointed out in the distance is typical. (The further away things are, the more information there is in the visual scene to sort out.) This becomes evident at the zoo when the affected child can only see the animals that are nearby. Busy environments like supermarkets, shopping centres or swimming pools can be difficult to handle. Children can react to these environments in different ways. They can become frightened or they can become disruptive. In contrast, when such children are out on an open playing field, they become content and behaviour can improve significantly. The older child can have problems reading. Print size diminishes with each school year. This leads to progressive crowding of text, which in turn can lead to problems with reading because the text becomes too crowded.

The aim of management is to decrease the amount of incoming visual information at any one time. Providing toys in small numbers on a plain play mat helps the child to focus on one thing at a time. A plain bed cover makes it much easier to find clothes on the bed than a patterned one. Going shopping when it is quiet is much easier. At school, recognition of how much the child is able to handle at any one time facilitates the development and delivery of the curriculum. Enlargement of the text to reduce crowding can help significantly. Correction of small degrees of hypermetropia can provide slight enlargement and thereby decrease crowding. For more severe problems, text can either be masked off so that only a small amount at a time is shown or it can be shown sequentially on a computer screen.
Difficulties with visually guided movement of the limbs Moving accurately through three-dimensional space requires intact dorsal stream function. Children with periventricular white matter damage or posterior parietal damage due to other causes can manifest profound difficulties in moving through three-dimensional visual space. ${ }^{98}$ Inability to differentiate a floor boundary (for example, between carpet and linoleum) means that any such boundary that has not been seen before has to be investigated to determine whether there is a step present or not. Black and white tiled floors can be frightening. When approaching a kerb, the foot may be lifted to the wrong height, too early or too late. Going down stairs is particularly difficult because of the difficulty in judging depth. A banister helps considerably by providing tactile and proprioceptive depth information. Inaccuracy of reach and grasp, while less common, can also be seen. In a recent review of our patients we have identified 40 children with this problem (commonly associated with impaired simultaneous perception) including eight with intact stereopsis, which suggests that the dorsal stream visual pathways serving motion through threedimensional space may be distinct from the pathways serving stereoscopic vision.

Problems pursuing the target A common association with impaired simultaneous perception and impaired visually guided movement is inaccurate supranuclear control of gaze. ${ }^{34}$ There may be inaccurate saccades and problems with pursuit in such children with brain damage. ${ }^{99}$ To what extent this impairs perception of moving targets remains to be elucidated.

Not recognising people and objects Ventral stream dysfunction associated with difficulty recognising faces is a common feature of damage in the temporal lobe territory. ${ }^{98}$ The problem may manifest in different ways, ranging from inability to recognise close family members, to consistent problems of not recognising people when they are seen out of context. Incorrect identification of strangers as being known is typical. Children can become adept at recognising people by voice recognition and other cues. It is only when the other cues are not available, such as a mother standing in a group waiting for her child at a nursery, that the problem becomes apparent when the child runs to the wrong parent. These children are commonly unable to understand the language conveyed by facial expression and may be incorrectly diagnosed as being autistic. A simple test of asking the child to tell you whether you are happy, cross or sad as you adopt the appropriate expressions is very informative. Use of obvious and 
Table 2 History taking strategies to diagnose cerebral visual impairment in children

\section{Dorsal stream/posterior parietal dysfunction}

Impaired simultaneous perception

The presence of symptoms

- Difficulty seeing things that are pointed out in the distance. (The greater the distance, the greater the complexity of the visual scene.)

Affected children are unable to identify objects pointed out to them in the distance even if they are apparently obvious, such as a tractor on the other side of the road.

- Difficulty seeing mother when she is waiting at school, for example, amongst other parents.

The scene can be too crowded to see mother

- Difficulty coping in a busy supermarket.

Two forms of behaviour are common. The child may either be very frightened or may run around in an uncontrolled manner.

- Difficulty coping in a busy swimming pool.

The sound and crowding can be overwhelming leading to fear and panic.

- Finding a chosen toy in a toy box or from among other toys (foreground clutter).

Typically an affected child is unable to find a chosen toy. The toy box may be emptied out by the child but the chaotic scene prevents any structured play, and the child is easily distracted.

- Finding an object that is on a patterned background.

Even large and obvious objects such as a cat may not be seen on a patterned bedspread or a patterned carpet.

- Playing team sports.

The older child with cerebral visual impairment only can have great difficulty handling team sports.

The reduction of symptoms

- Improvement in behaviour in 'visually quiet' environments.

When in tidy rooms with little furniture and little decoration the child becomes attentive and much less distractible.

- Open spaces.

When out in the country or in open spaces such as a park or playing field the child again becomes attentive and calmer.

- One to one communication in quiet environments.

The performance of the child can improve considerably.

Impaired movement through three-dimensional space (optic ataxia)

Lower limbs

- Tripping and walking over things.

A young child may walk over toys as if they are not there. (This can also indicate lower visual field impairment).

- Difficulty walking over uneven ground.

The carers automatically take the hand of an affected child when they come to uneven ground. (If the child holds onto the elbow, as in leading a blind person, the uneven ground becomes easier to navigate.)

- Problems with kerbs.

Going down, the kerb may not be seen and the child may walk off the end of the kerb.

Going up, the foot can be raised too early or too late; too high or too low.

- Problems with floor boundaries (eg between carpet and linoleum).

The child stops at boundaries (that are not already known) and feels the boundary with a foot or a hand.

- Problems with stairs.

Going up stairs is easier than going down.

Both hands may be used to hold onto the banister.

Upper limbs

- Inaccurate reaching.

Reaching is intermittently accurate. Things are often knocked over. Reaching can be short or long of the target.

Impaired perception of movement

- Film and TV

Only films with limited motion are watched.

- Seeing moving targets.

Small fast animals can cause a fright because they seem to appear from nowhere when they stop.

Ventral stream/temporal lobe dysfunction

Impaired recognition of faces

- Not recognising people who are known.

Individual family members are not recognised until they speak.

(Differentiate from impaired simultaneous perception when a family member in a group of people may not be seen or recognised.)

- Incorrectly recognising people who are unknown.

Strangers may be greeted as known individuals. 
Table 2 (continued)

Impaired recognition of the language components of facial expression

- May not be able to tell the difference between, for example, a smile and a frown.

This may accompany impaired face recognition.

Impaired recognition of shape

- Can only tell one car from another by colour and not by shape.

This may occur in isolation but more commonly accompanies impaired object recognition.

Inability to name colours

- Colour matching is, however, intact. This accompanies left occipito-temporal damage.

Linking the colour to an appropriate noun is effective management (eg lemon yellow, and grass green).

Impaired reading

- Great problems learning to read (see Table 1).

Disorientation

- The child easily gets lost. It takes a long time to find the way around school. Things cannot be found around the house. (Everything has to have its place.)

Poor visual memory

- Copying is very difficult and the child finds it difficult to learn information with a visual basis.

subtle expressions helps to detect less obvious difficulties. (It is also really worthwhile doing this test for all visually impaired children to determine the facial expression recognition distance. Children who cannot see well often look impassive and may be thought to be poorly responsive, but they can only emulate and respond to what they see.) Difficulties recognising shape and form have also been described. ${ }^{98,100}$ Such children can have problems with geometry but cope well with other aspects of maths. They may also have reading difficulties related to letter and word recognition. ${ }^{101}$

Difficulty reading The cognitive processes that are required for reading are complex, but in the context of the child who has neurological pathology here are a few practical points that may prove helpful:

- Text needs to be at the size that can be read at maximum speed when the child is tired. (Not at the level of the visual acuity, which is a measure of the smallest text that can be seen.) One must not forget that print size diminishes as each year at school passes.

- Check accommodation by dynamic retinoscopy in children with cerebral palsy. ${ }^{102}$ We have found that it can be absent in children with dyskinetic cerebral palsy $^{103}$ or reduced in other forms of cerebral palsy and a near reading correction can improve reading vision tremendously.

- Rarely impaired supranuclear control of gaze can preclude the small eye movements needed for letter by letter reading. Both enlargement of the text and learning to read by the look and say method can prove helpful.
- Ventral stream pathology can lead to great problems recognising letters and words, and it is important that children with such pathology are enabled to access information by other methods than reading.

- Dorsal stream pathology causing impaired simulta neous perception leads to an extreme form of crowd ing. The acuity may be normal for single letters but it is profoundly reduced for crowded letters. The teachers often discover that such children can read single words when other text is masked off and sequential presentation of text on a computer screen or by using two black L-shaped occluders can be very effective.

- Rarely pathology of the left occipital lobe and the splenium of the corpus callosum means that the word seen by the right occipital lobe cannot be passed to the language brain on the left side and this leads to alexia. Braille has even been advocated in such cases.

Getting lost Problems with route finding, which can vary in severity, commonly accompany impaired face recognition both in children and in adults (and may be associated with a left homonymous hemianopia). ${ }^{98}$ There may be difficulties when out and about, problems finding the way within buildings, for example at school and difficulties remembering where things are kept.

When out and about important routes can be committed to memory by using verbal cues and it can be helpful to talk about landmarks on a regular basis. In the home, colour coding or labelling of doors and drawers can help considerably. 
Problems with visual memory Visual memory is used for copying, drawing, remembering where things are and a host of other tasks. Educational strategies are required, which take these problems into account in children with visual memory difficulties.

Examples of cerebral visual impairment in children $\mathrm{TN}$ is 5 years old. He and his twin brother were born at 24 weeks gestation. He frequently falls and trips over things. (Suggestive of lower visual field impairment.) He commonly walks straight into door frames or even lamp-posts (which is suggestive of optic ataxia). $\mathrm{He}$ cannot find a toy in a pile of toys. He cannot see something pointed out in the distance and he runs around in an uncontrolled manner in supermarkets. (These features suggest impaired simultaneous perception.) The visual acuities are 6/12 right and 6/60 left due to left myopia and anisometropic amblyopia.

The visual history and premature twin birth are typical of periventricular leukomalacia affecting the occipital white matter. This was confirmed by MRI scan (Figure 4) which shows a subtle white matter signal in both parieto-occipital ventricular areas and mild dilatation of the right lateral ventricle trigone. There is less white matter in the occipital than in the frontal regions.

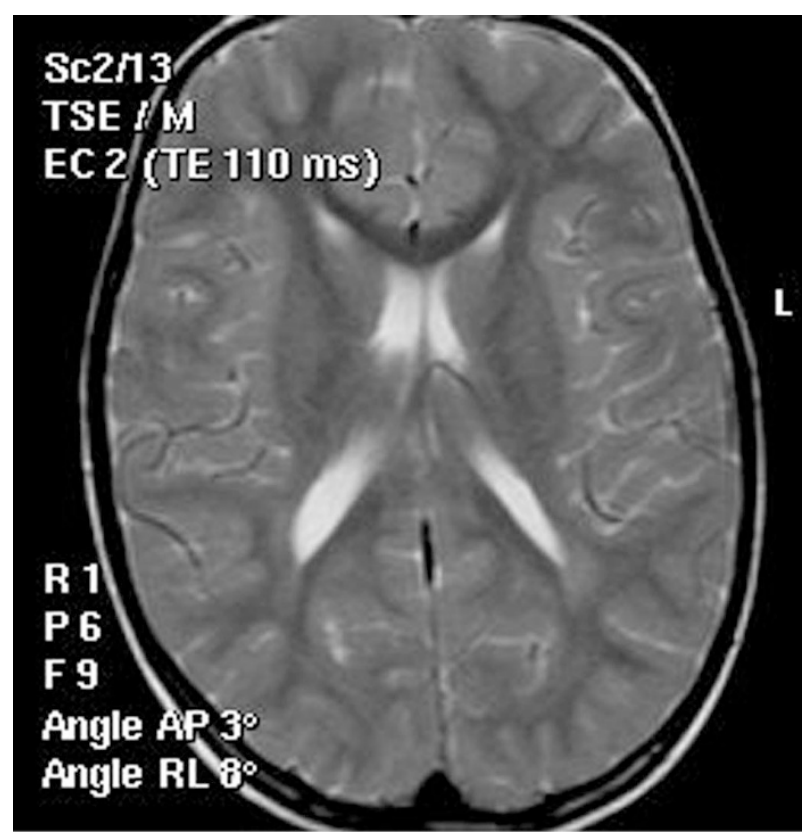

Figure 4 Axial MRI scan showing mild dilatation of the right lateral ventricle associated with an abnormal white matter signal in the parieto-occipital areas, and less white matter in the occipital than in the frontal areas.
KS is eight years old. She first presented with a divergent squint at the age of 20 months, but the clue to her higher visual dysfunction came with the history that as a toddler she consistently tripped over obstacles, including her baby sister. She has visual acuities of 6/12 and bilateral peripheral lower visual field restriction. Even when she is looking down, she is sometimes inaccurate in moving her feet over an irregular surface. She can have difficulty with floor boundaries between linoleum and carpet and tests the boundary with her feet to make sure that there is not a step. She manages well with steps and stairs but she has to hold on to the banister. Occasionally, she mis-reaches for objects with either hand. She may either reach too near or too far. She has problems handling complex visual scenes. She has difficulty seeing things which are pointed out to her in the distance (the further things are away, the more detail there is to see). She has had difficulty finding a toy in a toy box (but this is improving) and may easily lose an object on a patterned carpet. When playing a board game, she can 'lose' her own counter and has to have her attention drawn to it. She has difficulty in visiting shops and supermarkets because she finds them too crowded and she prefers to avoid them. Educational material has to be simplified because when it is complicated, she can miss out a lot of information. She can easily lose her way. This applies particularly when she is out and about and she has to be given help and directions on a regular basis. Her MRI scan (Figure 5) shows that she has sustained damage to the superior occipital lobes extending into the posterior parietal territory, the origin of which is unknown.

The recognition that $\mathrm{KS}$ has these problems has meant that people working with her understand the nature of her problems and are sympathetic to her needs.

Educational information is enlarged in order to reduce crowding and is presented sequentially. Her bedroom is decorated in a plain fashion and there is not a lot of clutter. She is also receiving training in how to find her way around.

AC was first seen by us at the age of 6 years. She had been born at term with a normal birth weight. She developed apnoeic seizures $24 \mathrm{~h}$ after birth. CT of the brain the following month showed areas of low attenuation in the frontal and parietal areas. As she grew up it became apparent that she was not seeing normally and MRI at the age of 5 years (Figure 6) showed loss of occipital cortex and white matter associated with enlargement of the trigone regions of the lateral ventricles. White matter damage was also seen in the parietal and frontal regions. These were thought to be consistent with hypoglycaemic or possibly hypoxic ischaemic encephalopathy. The visual acuities are 6/18 in each eye. Visual field examination reveals both lower 


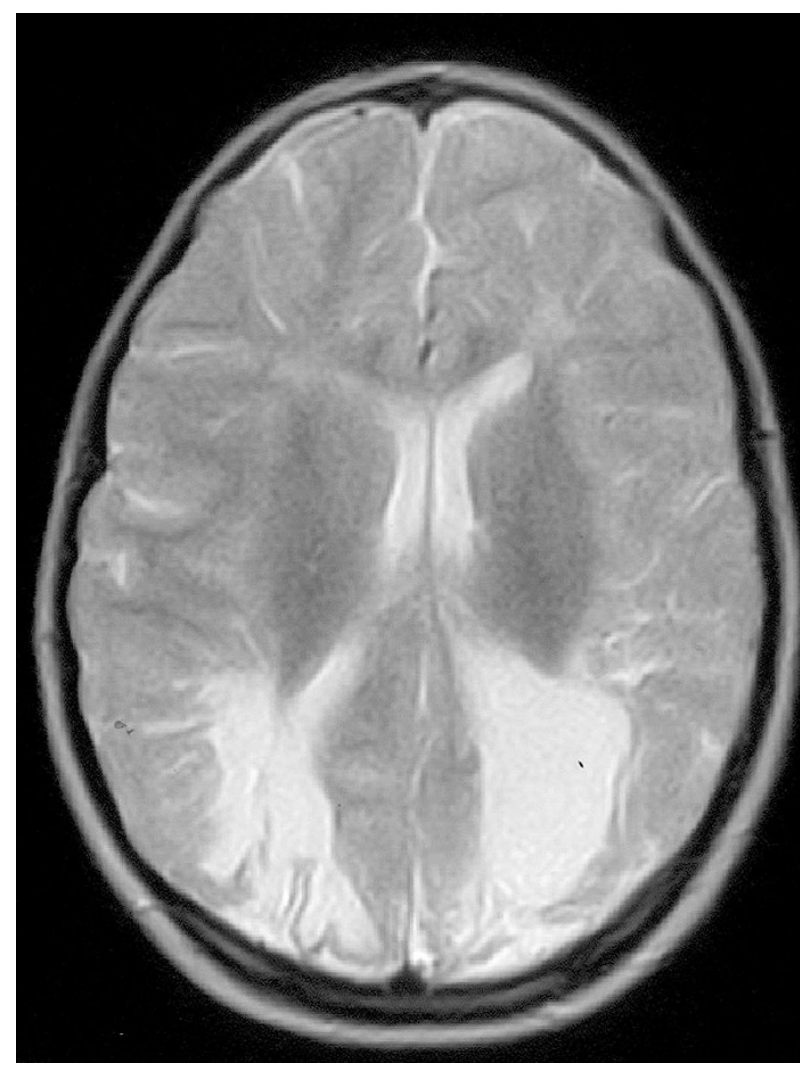

Figure 5 Coronal MRI scan of the posterior parietal area showing bilateral superior periventricular scarring and expansion of the lateral ventricles.

visual field loss and left-sided extinction. She finds slopes and stairs frightening and she moves her feet inaccurately over steps and kerbs. She also reaches for things inaccurately. Complex visual scenes are a problem and she too cannot cope in crowded environments, cannot see things which are pointed out in the distance and cannot find an item on a patterned background. She does not appear to see things which move quickly.

She does not recognise her mother or other family members and has difficulty recognising shapes, for example she has difficulty differentiating a slipper from a banana, and she has problems getting lost in new environments. Intermittently she performs like a sighted child when she is in a clear high contrast uncluttered well-known visual environment, and at other times she acts as profoundly visually impaired when in a complex visual scene which she has not previously experienced. After 5-10 min she tires very easily and shows strong avoidance behaviour. She can therefore only tolerate short bursts of working on visual tasks. Three years later she has learned to read using the look and say method. She chooses to read with a little window in a white mask which she moves across the text. This compensates for her impaired simultaneous perception. She uses her

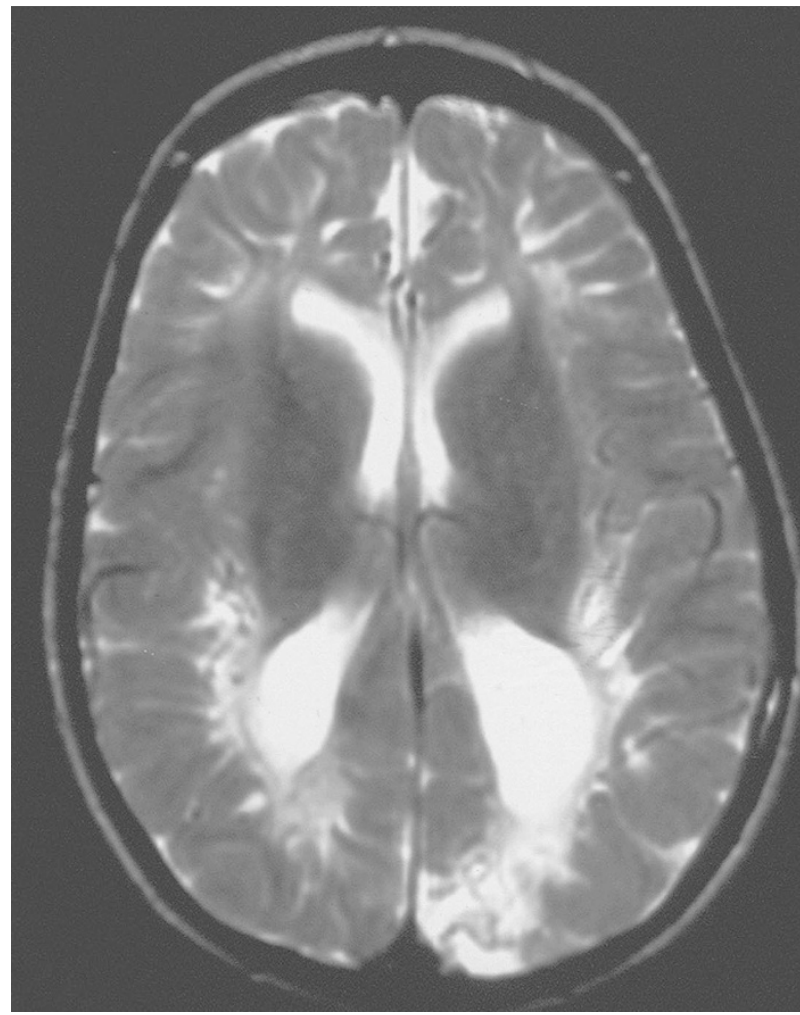

Figure 6 Axial MRI scan showing loss of white matter in the occipital cortex associated with enlargement of the trigone regions of the lateral ventricles. There is also frontal and parietal white matter damage.

memory for hairstyles to compensate for her inability to recognise faces, and all her friends know to introduce themselves. Her ability to see things pointed out from the car has improved considerably.

The most common missed diagnosis In our experience, the most common diagnosis of visual impairment in children to be missed is periventricular leukomalacia. The lack of periventricular white matter can cause cerebral palsy (particularly spastic diplegia), but it can cause visual problems in isolation. A combination of lower visual field impairment, impaired visually guided movement (particularly of the lower limbs), difficulty extracting visual information from a complex background (in various combinations and in varying degree) which may or may not be associated with motor problems, is common but the diagnosis is easily missed. Additional problems with impaired recognition and a tendency to easily get lost are often associated features.

Cognitive visual problems in children with cerebral palsy In children with cerebral palsy who can communicate and function socially, the above problems can be apparent in any combination and can be identified. In more 
profoundly affected children, however, it is very likely that they have cognitive visual problems in equal measure, but they cannot be identified because they are masked by communication and motor problems. However, it is a logical principle, in the context of the education of such children, to simplify the visual world by having limited visual information in the foreground and a plain background, recognising that simultaneous perception is likely to be limited.

\section{Cortical blindness and 'travel vision' A reflex visual} pathway connects the retina to the the superior colliculi and the pulvinar. This subsystem serves the ability to perceive and react to moving targets at a subconscious level. Some children who have profound loss of vision due to occipital pathology and who have cerebral blindness are nevertheless able to react to moving targets. For example a moving spoon brought in from the side (where reflex visual perception is arguably more effective), may result in the mouth opening. Such children who are mobile may be able to navigate successfully. This form of vision has been referred to as blindsight, ${ }^{29}$ and the navigational vision has been called travel vision. ${ }^{104}$ It appears to be a variable but fatiguable function and in our experience may begin to develop in an apparently blind child at about the age of 4 or 5 years.

\section{Conclusion}

In conclusion, we take it for granted that we know what we are looking at, that we can find our way around and that our internal percept of the visual world around us provides an accurate three-dimensional map to visually guide all our movements, but when these systems become dysfunctional, profound problems arise. Impaired recognition of people and objects and difficulty route finding typify the ventral stream (temporal lobe) disorders, whilst problems extracting focal information from complex visual scenes and disordered visually guided movements are the hallmark of dorsal stream (posterior parietal) disorders. By recognising the triggers which lead to suspicion of these conditions and their differential diagnoses, and adopting a structured approach to clinical history taking (from both patients and their carers) accurate diagnoses can be made, and optimal management implemented for both adults and children.

\section{References}

1 Grusser O-J, Landis T. Visual agnosias and other disturbances of visual perception and cognition. In: Cronly Dillon JR (ed). Vision and Visual Dysfunction. vol. 12. Macmillan Press: London, 1991.

2 Stasheff SF, Barton JJ. Deficits in cortical visual function. Ophthalmol Clin North Am 2001; 14: 217-242.
3 Milner AD, Goodale MA. The Visual Brain in Action. Oxford University Press: Oxford, 1995.

4 Blouin J, Vercher JL, Gauthier GM, Paillard J, Bard C, Lamarre Y. Perception of passive whole-body rotations in the absence of neck and body proprioception. J Neurophysiol 1995; 74: 2216-2219.

5 Weir CR. Spatial localisation: does extraocular muscle proprioception play a role? Graefes Arch Clin Exp Ophthalmol 2000; 238: 868-873.

6 Rubin AM, Woolley SM, Dailey VM, Goebel JA. Postural stability following mild head or whiplash injuries. Am J Otol 1995; 16: 216-221.

7 Weir CR, Cleary M, Parks S, Barrie T, Hammer HM, Murdoch J. Spatial localization after different types of retinal detachment surgery. Invest Ophthalmol Vis Sci 2001; 42: $1495-1498$.

8 Sergent J, Villemure JG. Prosopagnosia in a right hemispherectomized patient. Brain 1989; 112: 975-995

9 Young AW. Face recognition impairments. Philos Trans $R$ Soc London B Biol Sci 1992; 335(1273): 47-53.

10 Evans JJ, Heggs AJ, Antoun N, Hodges JR. Progressive prosopagnosia associated with selective right temporal lobe atrophy. A new syndrome? Brain 1995; 118: 1-13.

11 Takahashi N, Kawamura M, Hirayama K, Shiota J, Isono O. Prosopagnosia: a clinical and anatomical study of four patients. Cortex 1995; 31: 317-329.

12 McCarthy RA, Evans JJ, Hodges JR. Topographic amnesia: spatial memory disorder, perceptual dysfunction, or category specific semantic memory impairment? J Neurol Neurosurg Psychiatry 1996; 60: 318-325.

13 Barton JJ, Cherkasova M, O'Connor M. Covert recognition in acquired and developmental prosopagnosia. Neurology 2001; 57: 1161-1168.

14 Shen L, Hu X, Yacoub E, Ugurbil K. Neural correlates of visual form and visual spatial processing. Hum Brain Mapp 1999; 8: 60-71.

15 Tarkiainen A, Helenius P, Hansen PC, Cornelissen PL, Salmelin R. Dynamics of letter string perception in the human occipitotemporal cortex. Brain 1999; 122: 119-132.

16 Sergent J, Ohta S, MacDonald B. Functional neuroanatomy of face and object processing. A positron emission tomography study. Brain 1992; 115: 15-36.

17 Braddick OJ, O’Brien JM, Wattam-Bell J, Atkinson J, Turner $\mathrm{R}$. Form and motion coherence activate independent, but not dorsal/ventral segregated, networks in the human brain. Curr Biol 2000; 10: 731-734.

18 Nobre AC, Allison T, McCarthy G. Word recognition in the human inferior temporal lobe. Nature 1994; 372(6503): 260-263.

19 Mellet E, Tzourio N, Denis M, Mazoyer B. Cortical anatomy of mental imagery of concrete nouns based on their dictionary definition. Neuroreport 1998; 9: 803-808.

20 Courtney SM, Ungerleider LG, Keil K, Haxby JV. Transient and sustained activity in a distributed neural system for human working memory. Nature 1997; 10(386): 608-611.

21 Ungerleider LG, Courtney SM, Haxby JV. A neural system for human visual working memory. Proc Natl Acad Sci USA 1998; 95: 883-890.

22 Miyashita Y, Hayashi T. Neural representation of visual objects: encoding and top-down activation. Curr Opin Neurobiol 2000; 10: 187-194.

23 Diaper CJM. Pulfrich revisited. Surv Ophthalmol 1997; 41: 493-499. 
24 Heron G, Dutton GN. The Pulfrich phenomenon and its alleviation by a neutral density filter. Br J Ophthalmol 1989; 73: 1004-1008.

25 Heron G, Dutton GN. The management of visual symptoms related to the Pulfrich effect. Optician 1993; 205: 16-19.

26 Holmes G. Disturbances of vision caused by cerebral lesions. Br J Ophthalmol 1918; 2: 353-384.

27 Holmes G. Disturbances of visual orientation. $\mathrm{Br}$ J Ophthalmol 1918; 2: 449-468, 506-516.

28 Riddoch G. Dissociation of visual perception due to occipital injuries with especial reference to the appreciation of movement. Brain 1917; 40: 15.

29 Weiskrantz L. Blindsight: A Case Study and Implications. Oxford University Press: Oxford, 1998.

30 Zihl J. Neuropsychological Rehabilitation. A Modular Handbook. Rehabilitation of Visual Disorders After Brain Injury. Psychology Press: East Sussex, 2001.

31 Rizzo M, Robin DA. Simultanagnosia: a defect in sustained attention yields insights on visual information processing Neurology 1990; 40: 447-455.

32 Harvey M. Psychic paralysis of gaze, optic ataxia and spatial disorder of attention by Rudolph Balint. Cog Neuropsychol 1995; 12: 265-282.

33 Perez FM, Tunkel RS, Lachmann EA, Nagler W. Balint's syndrome arising from bilateral posterior cortical atrophy or infarction: rehabilitation strategies and their limitation. Disabil Rehabil 1996; 18: 300-304.

34 Jacobson LK, Dutton GN. Periventricular leukomalacia: an important cause of visual and ocular motility dysfunction in children. Surv Ophthalmol 2000; 45: 1-13.

35 Owsley C, Ball K, McGwin G, Sloane ME, Roenker DL, White MF et al. Visual processing impairmen and risk of motor vehicle crash among older adults. JAMA 1998; 279: 1083-1088.

36 Shah NJ, Marshall JC, Zafiris O, Schwab A, Zilles K, Markowitsch $\mathrm{HJ}$ et al. The neural correlates of person familiarity. A functional magnetic resonance imaging study with clinical implications. Brain 2001; 124: 804-815.

37 Nakamura K, Kawashima R, Sato N, Nakamura A, Sugiura $\mathrm{M}$, Kato $\mathrm{T}$ et al. Functional delineation of the human occipito-temporal areas related to face and scene processing. A PET study. Brain 2000; 123: 1903-1912.

38 Sergent J, Signoret JL. Varieties of functional deficits in prosopagnosia. Cereb Cortex 1992; 2: 375-388.

39 Mattson AJ, Levin HS, Grafman J. A case of prosopagnosia following moderate closed head injury with left hemisphere focal lesion. Cortex 2000; 36: 125-137.

40 Marotta JJ, Genovese CR, Behrmann M. A functional MR study of face recognition in patients with prosopagnosia. Neuroreport 2001; 12: 1581-1587.

41 Wada Y, Yamamoto T. Selective impairment of facial recognition due to a haematoma restricted to the right fusiform and lateral occipital region. J Neurol Neurosurg Psychiatry 2001; 71: 254-257.

42 Trobe JR, Bauer RM. Seeing but not recognizing. Surv Ophthalmol 1986; 30: 328-336.

43 Tohgi $\mathrm{H}$, Watanabe K, Takahashi H, Yonezawa H, Hatano K, Sasaki T. Prosopagnosia without topographagnosia and object agnosia associated with a lesion confined to the right occipitotemporal region. J Neurol 1994; 241: 470-474.

44 Rapcsak SZ, Polster MR, Glisky ML, Comer JF. False recognition of unfamiliar faces following right hemisphere damage: neuropsychological and anatomical observations. Cortex 1996; 32: 593-611

45 Gauthier I, Behrmann M, Tarr MJ. Can face recognition really be dissociated from object recognition? J Cogn Neurosci 1999; 11: 349-370.

46 Davidoff J, Landis T. Recognition of unfamiliar faces in prosopagnosia. Neuropsychologia 1990; 28: 1143-1161.

47 Young AW, Ellis HD. Childhood prosopagnosia. Brain Cogn 1989; 9: 16-47.

48 Ariel R, Sadeh M. Congenital visual agnosia and prosopagnosia in a child: a case report. Cortex 1996; 32 221-240.

49 Jones RD, Tranel D. Severe developmental prosopagnosia in a child with superior intellect. J Clin Exp Neuropsychol 2001; 23: 265-273.

50 Nunn JA, Postma P, Pearson R. Developmental prosopagnosia: should it be taken at face value? Neurocase 2001; 7: 15-27.

51 Bentin S, Deouell LY, Soroker N. Selective visual streaming in face recognition: evidence from developmental prosopagnosia. Neuroreport 1999; 10: 823-827.

52 Martins IP, Cunha e Sa M. Loss of topographic memory and prosopagnosia during migraine aura. Cephalalgia 1999; 19: 841-843.

53 Pomeranz HD, Lessell S. Palinopsia and polyopia in the absence of drugs or cerebral disease. Neurology 2000 22; 54: 855-859.

54 Santhouse AM, Howard RJ, Ffytche DH. Visual hallucinatory syndromes and the anatomy of the visual brain. Brain 2000; 123: 2055-2064.

55 Auzou P, Ozsancak C, Miret N, Hitzel A, Hannequin D. Palinopsia associated with partial seizures secondary to right parietal hemorrhage. Ann Med Interne (Paris) 1998; 149: 161-163.

56 Meadows JC, Munro SS. Palinopsia. J Neurol Neurosurg Psychiatry 1977; 40: 5-8.

57 Michel EM, Troost BT. Palinopsia: cerebral localization with computed tomography. Neurology 1980; 30: 887-889.

58 Lazaro RP. Palinopsia: rare but ominous symptom of cerebral dysfunction. Neurosurgery 1983; 13: 310-313.

59 Muller T, Buttner T, Kuhn W, Heinz A, Przuntek H. Palinopsia as sensory epileptic phenomenon. Acta Neurol Scand 1995; 91: 433-436.

60 Kupersmith MJ, Berenstein A, Nelson PK, ApSimon HT, Setton A. Visual symptoms with dural arteriovenous malformations draining into occipital veins. Neurology 1999; 52: 156-162.

61 Hori H, Terao T, Nakamura J. Visual perseveration: a new side effect of maprotiline. Acta Psychiatr Scand 2000; 101: 476-477.

62 Faber RA, Benzick JM. Nafazodone-induced palinopsia. J Clin Psychopharmacol 2000; 20: 275-276.

63 Lauterbach EC, Abdelhamid A, Annandale JB. Posthallucinogen-like visual illusions (palinopsia) with risperidone in a patient without previous hallucinogen exposure: possible relation to serotonin 5HT2a receptor blockade. Pharmacopsychiatry 2000; 33: 38-41.

64 Kawasaki A, Purvin V. Persistent palinopsia following ingestion of lysergic acid diethylamide (LSD). Arch Ophthalmol 1996; 114: 47-50.

65 McGuire PK, Cope H, Fahy TA. Diversity of psychopathology associated with use of 3,4methylenedioxymethamphetamine ('Ecstasy'). $\mathrm{Br} \mathrm{J}$ Psychiatry 1994; 165: 391-395. 
66 Gates TJ, Stagno SJ, Gulledge AD. Palinopsia posing as a psychotic depression. Br J Psychiatry 1988; 153: 391-393.

67 Silva JA, Tekell JL, Penny G, Bowden CL. Resolution of palinopsia with carbamazepine. J Clin Psychiatry 1997; 58: 30.

68 Beversdorf DQ, Heilman KM. Progressive ventral posterior cortical degeneration presenting as alexia for music and words. Neurology 1998; 50: 657-659.

69 Keri S, Antal A, Kalman J, Janka Z, Benedek G. Early visual impairment is independent of the visuocognitive and memory disturbances in Alzheimer's disease. Vision Res 1999; 39: 2261-2265.

70 Cormack FK, Tovee M, Ballard C. Contrast sensitivity and visual acuity in patients with Alzheimer's disease. Int J Geriatr Psychiatry 2000; 15: 614-620.

71 Trick GL, Trick LR, Morris P, Wolf M. Visual field loss in senile dementia of the Alzheimer's type. Neurology 1995; 45: 68-74.

72 Duffy CJ, Tetewsky SJ, O'Brien H. Cortical motion blindness in visuospatial AD. Neurobiol Aging 2000; 21: 867-869.

73 Cogan DG. Visuospatial dysgnosia. Am J Ophthalmol 1979; 88: 361-368.

74 Hof PR, Bouras C, Constantinidis J, Morrison JH. Balint's syndrome in Alzheimer's disease: specific disruption of the occipito-parietal visual pathway. Brain Res 1989 31; 493 368-375.

75 Mendez MF, Turner J, Gilmore GC, Remler B, Tomsak RL. Balint's syndrome in Alzheimer's disease: visuospatial functions. Int J Neurosci 1990; 54: 339-346.

76 Graff-Radford NR, Bolling JP, Earnest IV F, Shuster EA, Caselli RJ, Brazis PW. Simultanagnosia as the initial sign of degenerative dementia. Mayo Clin Proc 1993; 68: 955-964.

77 Mendez MF, Cherrier MM. The evolution of alexia and simultanagnosia in posterior cortical atrophy. Neuropsychiatry Neuropsychol Behav Neurol 1998; 11: 76-82.

78 Ardila A, Rosselli M, Arvizu L, Kuljis RO. Alexia and agraphia in posterior cortical atrophy. Neuropsychiatry Neuropsychol Behav Neurol 1997; 10: 52-59.

79 Delamont RS, Harrison J, Field M, Boyle RS. Posterior cortical atrophy. Clin Exp Neurol 1989; 26: 225-227.

80 Freedman L, Costa L. Pure alexia and right hemiachromatopsia in posterior dementia. J Neurol Neurosurg Psychiatry 1992; 55: 500-502.

81 Fletcher WA. Ophthalmological aspects of Alzheimer's disease. Curr Opin Ophthalmol 1994; 5: 38-44.

82 Fujimori M, Imamura T, Yamashita H, Hirono N, Mori E. The disturbances of object vision and spatial vision in Alzheimer's disease. Dement Geriatr Cogn Disord 1997; 8: 228-231.

83 Dixon MJ, Bub DN, Chertkow H, Arguin M. Object identification deficits in dementia of the Alzheimer type: combined effects of semantic and visual proximity. J Int Neuropsychol Soc 1999; 5: 330-345.

84 Giannakopoulos P, Gold G, Duc M, Michel JP, Hof PR, Bouras C. Neuroanatomic correlates of visual agnosia in Alzheimer's disease: a clinicopathologic study. Neurology 1999; 52: 71-77.
85 Kaskie B, Storandt M. Visuospatial deficit in dementia of the Alzheimer type. Arch Neurol 1995; 52: 422-425.

86 Caselli RJ. Visual syndromes as the presenting feature of degenerative brain disease. Semin Neurol 2000; 20: 139-144.

87 Rizzo M. Clinical assessment of complex visual dysfunction. Semin Neurol 2000; 20: 75-87.

88 Rizzo M, Anderson SW, Dawson J, Nawrot M. Vision and cognition in Alzheimer's disease. Neuropsychologia 2000; 38: 1157-1169.

89 Tetewsky SJ, Duffy CJ. Visual loss and getting lost in Alzheimer's disease. Neurology 1999; 23(52): 958-965.

90 Cogan DG. Visual disturbances with focal progressive dementing disease. Am J Ophthalmol 1985; 15(100): 68-72.

91 Laatu S, Revonsuo A, Hamalainen P, Ojanen V, Ruutiainen J. Visual object recognition in multiple sclerosis. J Neurol Sci 2001; 185: 77-88.

92 Okuda B, Tanaka H, Tachibana H, Iwamato Y, Takeda M, Sugita M. Visual form agnosia in multiple sclerosis. Acta Neurologica Scand 1996; 94: 38-44.

93 Vleugels L, Lafosse C, van Nunen A, Nachtergaele S, Ketelaer $\mathrm{P}$, Charlier $\mathrm{M}$ et al. Visuoperceptual impairment in multiple sclerosis patients diagnosed with neuropsychological tasks. Multiple Sclerosis 2000; 6: 241-254.

94 Menon GJ, Rahman I, Menon SJ, Dutton GN. The Charles Bonnet syndrome. Surv Ophthalmol Nov 2002.

95 Ffytche DH, Howard RJ, Brammer MJ, David A, Woodruff P, Williams $\mathrm{S}$. The anatomy of conscious vision: an fMRI study of visual hallucinations. Nat Neurosci 1998; 1: 738-742.

96 Weir CR, Cleary M, Parks S, Dutton GN. Spatial localization in esotropia: does extraretinal eye position information change? Invest Ophthalmol Vis Sci 2000; 41: 3782-3786.

97 Atkinson J. The Developing Visual Brain. Oxford University Press: Oxford, 1990.

98 Dutton G, Ballantyne J, Boyd G, Bradnam M, Day R, McCulloch D et al. Cortical visual dysfunction in children: a clinical study. Eye 1996; 10: 302-309.

99 Cassidy L, Taylor D, Harris C. Abnormal supranuclear eye movements in the child: a practical guide to examination and interpretation. Surv Ophthalmol 2000; 44: 479-506.

100 Houliston MJ, Taguri AH, Dutton GN. Evidence of cognitive visual problems in children with hydrocephalus: a structured clinical history-taking strategy. Dev Med Child Neurol 2000; 42: 298-306.

101 O'Hare AE, Dutton GN, Green D, Coull R. Evolution of a form of pure alexia without agraphia in a child sustaining occipital lobe infarction at $21 / 2$ years. Dev Med Child Neurol 1998; 40: 417-420.

102 Leat SJ. Reduced accommodation in children with cerebral palsy. Ophthal Physiol Opt 1996; 16: 385-390.

103 Ross LM, Heron G, Mackie R, McWilliam R, Dutton GN. Reduced accommodative function in dyskinetic cerebral palsy: a novel management strategy. Dev Med Child Neurol 2000; 42: 701-703.

104 Jan JE, Wong PK, Groenveld M, Flodmark O, Hoyt CS. Travel vision: "collicular visual system"? Pediatr Neurol 1986; 2: 359-362. 